\title{
COMMENTARY
}

\section{Acute liver failure and elevated troponin-l: controversial results and significance?}

\author{
Samir Jaber*1 and Catherine Paugam-Burtz ${ }^{2}$ \\ See related research by Audimooolam et al., http://ccforum.com/content/16/6/R228
}

\begin{abstract}
Acute liver failure in ICU patients is an often fatal condition in which many patients may die of multiple organ failure in the absence of liver transplantation. In this setting, cardiac injury may be associated with or precipitate a fatal outcome. Troponin-l is a wellestablished, specific, and sensitive surrogate of acute coronaropathy, with both diagnostic and prognostic value. Troponin-l elevation in acute liver failure patients is common, ranging from 60 to $75 \%$, and probably multifactorial. Despite a previous well-conducted US study showing that elevated troponin-l is associated with an independent risk of poor outcome and mortality, a recent UK study did not confirm these data and reported contradictory results. Troponin-I elevation observed in acute liver failure may therefore not represent true myocardial injury and may be better viewed as a marker of metabolic stress. The debate on the significance of elevated troponin-I in acute liver failure patients is revived.
\end{abstract}

\section{Introduction}

Severe acute liver failure (ALF) in ICU patients is an often fatal condition in which many patients may die of multiple organ failure in the absence of liver transplantation $[1,2]$. In this setting, cardiac injury may be associated with or precipitate a fatal outcome. Troponin-I is a wellestablished, specific, and sensitive surrogate of acute coronaropathy, with both diagnostic and prognostic value. Among selected groups with sepsis [3], or after surgery [4-7], troponin-I elevation has been shown to be related to the severity of illness - whereas in unselected

\footnotetext{
*Correspondence: s-jaber@chu-montpellier.fr

'Department of Anesthesiology and Critical Care B, Saint Eloi Teaching Hospital, University Montpellier 1, 80 avenue Augustin Fliche, Montpellier 34295 Cedex 5, France

Full list of author information is available at the end of the article
}

ICU patients, mortality among the troponin-I-positive group is higher irrespective of the cause of the troponin-I increase [8]. The role of troponin-I as an independent predictor of outcome has been debated in various clinical scenarios and studies [4-7]. Troponin-I elevation in ALF patients is common, ranging from 60 to $75 \%[9,10]$, and probably multifactorial. Despite a previous well-conducted US study showing that elevated troponin-I is associated with an independent risk of poor outcome and mortality, a recent UK study did not confirm these data and reported contradictory results. Troponin-I elevation observed in ALF may therefore not represent true myocardial injury and may be better viewed as a marker of metabolic stress. The debate on the significance of elevated troponin-I in ALF patients is revived.

Cardiac biomarkers may be helpful for early identification of more severe ALF patients and a significant elevation is associated with a poor outcome [10]. Troponin-I is a well-established, specific, and sensitive surrogate of acute coronaropathy, with both diagnostic and prognostic value. Studies performed in nonselected ICU patients reported that troponin-I elevation was associated with increased risk of morbidity and mortality despite an absence of acute coronary syndrome $[8,11]$. One US study including 187 patients with ALF showed that $74 \%$ of the admission serum samples tested were positive for troponin-I (cutoff value $>0.1 \mathrm{ng} / \mathrm{ml}$, range 0 to $50 \mathrm{ng} / \mathrm{ml}$ ) [10]. Although the pathogenesis and the significance of this elevation remain unclear, the authors showed a clear relationship between the level of troponin-I observed and the likelihood of a poor outcome; patients with elevated troponin-I levels had at least a twofold greater likelihood of advanced hepatic coma, arrhythmias, death, or liver transplantation. Moreover, an elevated Acute Physiology and Chronic Health Evaluation II score was correlated with higher troponin-I levels. In this US study, $91 \%$ of the patients who died had elevated troponin-I levels [10].

\section{Controversial results}

In the previous issue of Critical Care, Audimooolam and colleagues evaluated in an observational retrospective 
study the relationship that may exist between troponin-I, mortality, severity of illness, and nonhepatic organ failure in a cohort of ALF patients [9]. Among 278 consecutive patients screened during the study period (4 years), 218 $(78 \%)$ had troponin-I tested within the first 48 hours. Positive elevated troponin-I $(>0.05 \mu \mathrm{g} / \mathrm{l})$ was found in 136 patients $(62 \%)$ on ICU admission. Acetaminophen intoxication was the most common etiology for ALF. Mortality was higher in the troponin-I-positive patients in comparison with troponin-I-negative patients, but did not reach significance $(75 / 136=55 \%$ vs. $37 / 82=45 \%$, $P=0.195)$. Moreover, neither univariate nor multivariate analysis showed a significant correlation with outcome. Elevated troponin-I correlated closely with organ failure scores, renal failure, and vasoactive or inotropic drug use.

The authors concluded that - despite previous observations suggesting positive troponin-I is associated with an independent risk of poor outcome - their data suggest troponin-I positivity is an epiphenomenon of multiple organ failure that may not contribute independently to poor outcome, and that troponin-I elevation observed in ALF may not represent true myocardial injury and may be better viewed as a marker of metabolic stress.

\section{Why elevated troponin-I may be a poor independent predictor of outcome in ALF patients} Although the data reported in this UK study are of great interest among the liver failure literature [9], additional commentaries could be proposed (interpretation by the authors should be cautionary). The contradictory results between the present study from the UK [9] and Parekh and colleagues' study from the US [10] may indeed be explained by several different reasons. First, the definitions of ALF and the criteria for outcome are not detailed in the UK study and may be different between the studies. The dosage used and the definition of troponin-I elevation are also different between these two studies. Finally, the methodology and statistical analysis performed are different between the studies [9]. Moreover, poor outcome was considered in cases of liver transplantation and/or death. Mixing these two categories of patients might have been responsible for the discrepancies of the results between the two studies $[9,10]$.

\section{Future research and patient management}

Further research is required to fully evaluate the impact of troponin-I elevation on ICU admission but also the kinetic value during the ICU stay or after discharge [4]. The impact of troponin-I on the long-term prognosis after ICU discharge should be investigated. Further cardiac biomarkers should also be evaluated in the future in the ALF population, which may provide for better management.

\section{Abbreviations}

ALF, acute liver failure.

\section{Competing interests}

The authors declare that they have no competing interests.

\section{Author details}

'Department of Anesthesiology and Critical Care B, Saint Eloi Teaching Hospital, University Montpellier 1,80 avenue Augustin Fliche, Montpellier 34295 Cedex 5, France. 'Department of Anesthesiology and Critical Care, APHP Beaujon Hospital, 100 boulevard du Général Leclerc, 92110 Clichy, France.

Published: 14 January 2013

\section{References}

1. Kress JP, Rubin A, Pohlman AS, Hall JB: Outcomes of critically ill patients denied consideration for liver transplantation. Am J Respir Crit Care Med 2000, 162(2 Pt 1):418-423

2. Schiodt FV, Chung RT, Schilsky ML, Hay JE, Christensen E, Lee WM: Outcome of acute liver failure in the elderly. Liver Transp/ 2009, 15:1481-1487.

3. Ammann P, Fehr T, Minder El, Gunter C, Bertel O: Elevation of troponin I in sepsis and septic shock. Intensive Care Med 2001, 27:965-969.

4. Ausset S, Auroy Y, Verret C, Benhamou D, Vest P, Cirodde A, Lenoir B: Quality of postoperative care after major orthopedic surgery is correlated with both long-term cardiovascular outcome and troponin Ic elevation. Anesthesiology 2010, 113:529-540.

5. Levy M, Heels-Ansdell D, Hiralal R, Bhandari M, Guyatt G, Yusuf S, Cook D, Villar JC, McQueen M, McFalls E, Filipovic M, Schünemann H, Sear J, Foex P, Lim W, Landesberg G, Godet G, Poldermans D, Bursi F, Kertai MD, Bhatnagar N, Devereaux PJ: Prognostic value of troponin and creatine kinase muscle and brain isoenzyme measurement after noncardiac surgery: a systematic review and meta-analysis. Anesthesiology 2011, 114:796-806.

6. Muehlschlegel JD: If a troponin falls in a forest but no one measures it, does it really matter? Anesthesiology 2011, 114:732-733.

7. Siniscalchi A, Gamberini L, Mordenti A, Bernardi E, Cimatti M, Riganello I, Toccaceli L, Vecchiatini T, Diamanti M, Faenza S: Postoperative troponin T elevation as a predictor of early acute kidney injury after orthotopic liver transplantation: a preliminary retrospective study. Transplant Proc 2012, 44:1999-2001.

8. Ammann P, Maggiorini M, Bertel O, Haenseler E, Joller-Jemelka HI, Oechslin E, Minder El, Rickli H, Fehr T: Troponin as a risk factor for mortality in critically ill patients without acute coronary syndromes. J Am Coll Cardiol 2003, 41:2004-2009.

9. Audimooolam VK, McPhail MJ, Sherwood R, Willars C, Bernal W, Wendon JA, Auzinger G: Elevated troponin I and its prognostic significance in acute liver failure. Crit Care 2012, 16:R228.

10. Parekh NK, Hynan LS, De Lemos J, Lee WM: Elevated troponin I levels in acute liver failure: is myocardial injury an integral part of acute liver failure? Hepatology 2007, 45:1489-1495.

11. Baillard C, Boussarsar M, Fosse JP, Girou E, Le Toumelin P, Cracco C, Jaber S, Cohen Y, Brochard L: Cardiac troponin I in patients with severe exacerbation of chronic obstructive pulmonary disease. Intensive Care Med 2003, 29:584-589.

doi:10.1186/cc11897

Cite this article as: Jaber S, Paugam-Burtz C: Acute liver failure and elevated troponin-l: controversial results and significance? Critical Care 2013, 17:102. 